\title{
Can the Piper Play this Tune?
}

SOME lame ducks come and some lame ducks go, but International Computers Limited is still with us. Exactly a year after the British government announced that it was lending the company $£ 14.2$ million in order that the impetus of its research and development programme be continued, Mr. Christopher Chataway with all the munificence characteristic of the present Conservative Administration, announced last week that the Government was again dipping its hand into its pocket to help the company. This time the scientists working in research and development with ICL are assured of support until 1976. The amount now offered is $£ 25.8$ million, or $£ 8.6$ million a year which, according to $\mathrm{Mr}$ Chataway, is of the "launching aid type" and is designed to ensure that ICL's work on this new range of computers, the first announcements of which are expected within a year, will continue.

Apart from the obvious question of whether in the long run such support does much good for the company, the critical question to be asked at this time is whether the British Government is sensible in providing massive support for a national computer company. Will ICL, or any other national computer company for that matter, ever be able to compete with the giants of the industry from the United States on their own terms even with massive government aid? The Commissioners of the European Economic Community, being realists for once, are in favour of mergers of national computing interests in order that Europe should have a strong computing industry. $\mathrm{Mr}$ Christopher Layton, Director for Advance Technological Industries at the EEC, a few months ago called for ICL to find a partner within Europe so that a sister consortium to the Siemens-Philips-CII unit would be available. But ICL has so far stubbornly rejected the entreaties of the EEC and the company, at present at least, seems to have no inclination for an association with any other company either inside or outside Europe. The government by continuously providing financial loans are indeed fostering the national rather than the international approach.

ICL, however, sees its future as being extremely rosy. In spite of the fact that the company's pre-tax profits have never exceeded $6 \%$ of the turnover, the Government is now convinced, after analysing the basis for ICL's growth predictions, that its total loan of $£ 40$ million will be repaid between 1977 and 1984 from profits that the company will make in excess of $7.5 \%$ of turnover. Not only is the company confident of its profit levels in the second half of the 1970s and early 1980s but it also stated that after 1976 it will not need any further financial assistance from the government.

On what is such confidence based? The computer industry is certainly booming at present but the lessons of the past few years should have taught everyone that periods of growth do come to an end-certainly 10 years is a very long time indeed to hope for prosperity in the computer industry to continue growing unabated. ICL is, of course, on the verge of announcing a new line of com- puters and part of the confidence ensuing from the company must be based on the hope that these computers will sweep the market, but it remains to be seen whether it will be an effective counter to lines produced by other manufacturers.

In view of the bubbling self-confidence of ICL it is no surprise that it has so far turned up its nose at the suggestion of an association with another European company although it is quick to point out that it is in constant touch with other computer manufacturers and that if a technological rather than a political link would seem expedient then it would be given all consideration. But ICL's confidence contrasts sharply with the feelings of the European Commission on the future of computer companies within Europe. It is far from clear whether even two large multi-national European companies could compete effectively with IBM, and even a single large European company would perhaps not be an effective foil to the American giants in the field. But in spite of this ICL is going it alone. Such courage deserves commendation and it is only to be hoped that all goes well. But the British tax payer is going to have to wait a long time indeed to see whether or not he is going to get his money back.

\section{Years Ago}

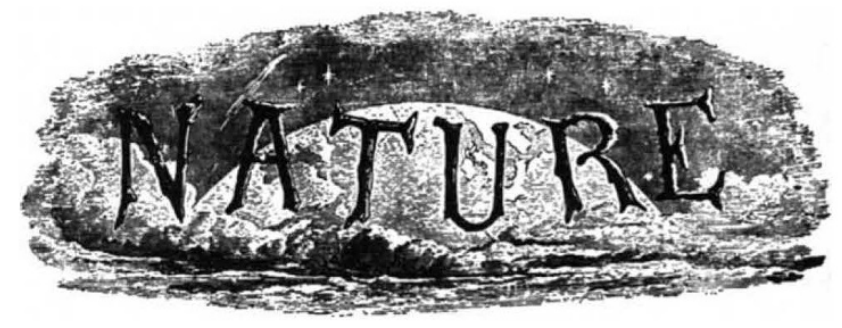

Curious Rainbow

AN unusual atmospherical effect was witnessed here to.day, which I had a good opportunity if observing. The sun was about $8^{\circ}$ from the horizon, shining brightly upon a heavy shower which had a background of dark clouds. The result was, of course, a double rainbow of remarkable brilliancy. In addition, howevir, to the ordinary circular and concentric bows, there was a third of an elliptical form, the two ends of which respectively sprang from the two ends of the inner arc, while the elliptical curve cut the outer arc at each extremity of a chord, which was parallel to, and which intersected the normal radius at a point about two-thirds of its length above, the diameter that formed the common base. The top of the elliptical bow was thus the outermost of the three, but the space between its inner margin and the outer margin of the second bow, although quite distinct, was not large.

The appearance of the third bow was due to light reflected from the sea. The sun being low, the resulting line of reflection was long, and it was the linear character of the scurce of light which gave the elliptical form to the bow it ozcasioned.

Dunskaith, Ross-shire, July ro GegraE J. Romanes

From Nature 8, 224, July 17, 1873. 